\title{
Enerji ve Ham Madde Korunumu Açısından Yapısal Atıkların Yeniden Kullanımına/Geri Dönüşümüne Yönelik Bir Değerlendirme
}

\author{
Burcu SALGIN ${ }^{1 *}$, Cahide AYDIN IPEKÇi ${ }^{2}$ (D) \\ Nilay COŞGUN ${ }^{3}$ iD , Tülay TIKANSAK KARADAYI 4 iD \\ ORCID 1: 0000-0001-6473-5549 - ORCID 3: 0000-0001-5874-3331 \\ ORCID 2: 0000-0003-3170-4628 - ORCID 4: 0000-0002-8502-695X \\ ${ }^{1}$ Erciyes Üniversitesi, Mimarlık Fakültesi, Mimarlık Bölümü, 38039, Kayseri, Türkiye. \\ 2, 3, 4 Gebze Teknik Üniversitesi, Mimarlık Fakültesi, Mimarlık Bölümü, 41400, Kocaeli, Türkiye. \\ *e-mail: bsalgin@erciyes.edu.tr
}

Öz

Enerji kaynaklarının ve ham madde rezervlerinin hızla azaldığı dikkate alınırsa bu alanda yaşanacak olası kısıtlar toplumların ekonomik koșullarını ve sosyal yaşamlarını olumsuz yönde etkileyebilecektir. Bu çalışma ile enerji ve ham madde korunumu açısından yapısal atıkların yeniden kullanım/geri dönüşüm potansiyeli vurgulanarak farkındalık yaratılması amaçlanmıştır. Örneğin beton üretiminde agrega olarak atık betonların kullanılması ham madde korunumu açısından önemlidir. Kimyasallarla boyanmadan kullanılan çelik ürünler geri dönüşüm evresinde daha az işlem gerektireceğinden enerji tüketiminin azalması mümkündür. Bu bağlamda enerji ve ham madde kullanımını azaltma hedefine ulaşmak için yapısal atık yönetimi ile ilgili konuları yapı endüstrisinin bir parçası olarak ele almak önemlidir.

Anahtar Kelimeler: Enerji korunumu, ham madde korunumu, yapısal atık, atık yönetimi

\section{An Evaluation on the Reusing/Recycling of C\&D Wastes in Terms of Energy and Raw Material Conservation}

\begin{abstract}
Considering that energy resources and raw material reserves are rapidly decreasing, potential crises may adversely affect the economic conditions and social lives of societies. In this study, it is aimed to create awareness by emphasizing the importance of reusing/recycling of construction and demolition (C\&D) waste in terms of energy and raw material conservation. For instance, waste concrete usage as aggregate is important to protect raw materials. Steel products which are not coating with chemicals will reduce energy consumption by requiring less processing during the recycling phase. In order to achieve the goal of reducing energy and raw material use, it is important to address the issues related to C\&D waste management as part of the building industry.
\end{abstract}

Keywords: Energy conservation, raw materials conservation, c\&d waste, waste management

\section{Giriş}

Yapı sektöründeki uygulamalar dünyada ve Türkiye'de hızla devam ederken beraberinde yapısal atıkların da oluşmasına sebep olmaktadır. Yapısal atıklar, yapı ürünlerinin ve yapının yaşamı boyunca ortaya çıkmaktadır. Doğal kaynakların 1/3'ünü tüketen yapı sektörünün, toplam katı atık üretiminin \%40'ından sorumlu olduğu ifade edilmektedir (Cengiz, Karadağ ve Alpay, 2014). Yapısal atıkların miktarca fazlalığı ve hacimce büyüklükleri çeşitli ülkelerde depolama alanlarının kapasitelerini

Citation/Atıf: Salgın, B., Aydın İpekçi, C., Coşgun, N. and Tıkansak Karadayı, T. (2021). Enerji ve ham madde korunumu açısından yapısal atıkların yeniden kullanımına/geri dönüşümüne yönelik bir değerlendirme. Journal of Architectural Sciences and Applications, 6 (2), 526-537.

DOI: https://doi.org/10.30785/mbud.927981 
zorlamakta, çevre sorunlarına yol açmaktadır. Bu atıkların oluşturduğu diğer bir sorun da enerji ve ham madde kayıplarıdır.

İnşaat sektöründe oluşan yapısal atık türlerinin değerlendirilme potansiyellerinin saptanması enerji ve ham madde korunumu, kirliliklerin azaltılması gibi çevresel ve ekonomik birçok yarar sağlamaktadır. Bu bağlamda çalışmanın dayandığı temel ilkeler;

- Enerji kullanımını azaltarak yapı ürünlerinin doğadan çıkarılması, işlenmesi ve bir şantiyeye taşınması süreçlerinde tüketilen enerjiyi kapsayan oluşum enerjisini korumak,

- Hammadde kullanımını azaltmaktır.

Yapısal atıkların uygun eylem adımları ile yönetilmesi durumunda enerji kayıplarının önüne geçilebilir ve ham madde korunumu sağlanabilir. Bu çalışma ile yapısal atık yönetiminin enerji ve ham madde korunumu açısından önemi vurgulanarak farkındalık yaratılması amaçlanmıştır. Bu farkındalık düzeyi ile yönetilecek olan atıkların çevre ve ekonomi üzerindeki olumsuz etkilerinin azalacağı öngörülmektedir.

Yapısal atık hiyerarşisinde ilk ve en önemli adım önleme/azaltmadır. Depolama alanlarına gönderilen atık miktarının önlenmesi, önlenemeyenlerin azaltılması ile çevresel ve ekonomik etkilerin azaltılması sağlanabilir. Atıkların geri dönüştürülmesi sonucu yeni ürün üretiminde ham madde olarak kullanılması ise enerji tüketiminin azaltılmasına ve yeniden kullanım ile oluşum enerjisinin korunmasına yardımcı olacaktır.

Hammadde kullanımını azaltmak için; yeniden kullanım (reuse) ve geri dönüşüm (downcycle, recycle, upcycle) önemlidir. Yeni üretimlerde kullanılmak için doğadan çıkarılan temiz ham maddeler nedeniyle doğa gün geçtikçe fakirleşmektedir. Bu noktada yeniden kullanım ile yeni ürün üretimi için harcanan ham maddelerin korunumu sağlanabilecektir. Geri dönüşüm ile atıkların yeni ürünlerin üretim süreçlerine katılarak işlenmesi gerçekleştirilecek, bir yapı ürünü beşikten mezara değil, beşikten beşiğe olarak adlandırılan bir döngü içerisinde kalacaktır. Böylece bir sürecin atığı yeni bir üretim sürecinin ham maddesi olacaktır.

Yeniden kullanım; yapı ürünlerinin ve yapı bileşenlerinin düzgün olarak sökülüp başka bir binada benzer amaç için kullanılmasıdır. Bu yöntemde en az düzeyde enerji tüketilmektedir. Bir döngünün atık olarak görülen çıktısı, diğer döngünün girdisi olarak kullanıldığından çevre açısından en yararlı yaklaşımdır.

Atıkların en aza indirilmesi uygulamalarının teşvik edilmesi, malzemelerin yeniden kullanımını artırmanın bir aracı olarak düşünülmektedir (Li, Chen ve Wong, 2003). İnşaat alanındaki atıkların azaltılmasında da başlıca amaç atık malzemelerin yeniden kullanımı olmalıdır. Bunun için proje yönetiminde etkili bir eş güdüme ve planlamaya gereksinim vardır (Ajayi ve diğerleri, 2017). Dünya genelinde yaygınlıkla kullanılan BREEAM ve LEED sertifikasyon sistemlerinde de yapının tamamen ya da kısmen yeniden kullanımı ve yapı ürünlerinin yeniden kullanımı önemli bir ölçüt olarak yer almaktadır (Building Research Establishment Environmental Assessment Method [BREEAM], 2016; Leadership in Energy and Environmental Design [LEED], 2019).

Yapısal atıkların yeniden kullanılabilmesi için yıkım sırasında yapı elemanları ve malzemelerinin en az zararla kurtarılması olan yapı sökümü (deconstruction) etkili bir yöntem olmaktadır. Yapı sökümü; yapıların düzenlenmesinde ve yıkılmasında yapı elemanlarının kurtarılması ya da yapı bileşenlerinin parça parça taşınması olarak tanımlanmaktadır. Söküm işlemlerinin yıkımdan farkı, dikkatli olarak ayrılan parçaların yeniden kullanılabilmeleridir. Yapıların yıkılması sonucunda ise malzemeler geri dönüştürülmekte ya da atık depolama alanlarına gönderilmektedir.

Geri dönüşüm; atık haline gelmiş yapı malzemelerinin başka uygulamalar için işlenmemiş malzeme/ham madde olarak kullanılmasıdır. Yeniden kullanılamayan malzemelerin geri dönüştürülmesi çok fazla işlem gerektirmeden az miktarda enerji tüketimiyle mümkündür. Çeşitli sertifikasyon sistemlerinde de yapısal atıkların geri dönüştürülmesi ve yeni yapımlarda geri dönüşümlü içeriği olan ürün kullanımı bir ölçüt olarak yer almaktadır (BREEAM, 2016; LEED, 2019). 
Yapısal atıkların başarılı geri dönüşüm uygulamaları için, bu atıkların miktarına ve kalitesine ilişkin ayrıntıı bilgiler önemlidir. Farklı zaman dilimlerinde kullanılan ve farklı bölgelerden toplanan çeşitli yapı malzemelerine bağı olarak oluşan atıkların kompozisyonundaki sürekli değişiklikler, geri dönüşüm yöntemlerini de etkileyecektir (Huang, Lin, Chang ve Lin, 2002).

Yapısal atıklar yüksek oranda geri dönüştürülebilir malzemeler içermekle birlikte yıkımlar sonucu karışık biçimde bulunmaları geri dönüşümü zorlaştırır. Geri dönüştürülecek atıkların kaynağında uygun bir şekilde sınıflandırılmasıyla geri dönüşüm oranı artabilmektedir. Seçici yıkım yani betonarme parçaların, tehlikeli atıkların ve geri dönüştürülecek maddelerin ayrı ayrı yıkımı da geri dönüşüm oranını ve kalitesini yükseltir. Bazı alanlarda ise tehlikeli maddeleri kaynaktan uzaklaştırmak için ayırma işleminin, kaynaktan uzakta, örneğin ayırma ve sıkıştırarak ezme merkezlerinde yapılması önemlidir.

\section{Yöntem}

Çalışmanın literatür taraması Erciyes Üniversitesi Bilimsel Araştırma Projeleri Koordinasyon Birimi tarafından desteklenen ve 2018 yılında tamamlanan FBA-2016-6627 no.lu araştırma projesi kapsamında yapılmıştır. Yapısal atık yönetimi, yapısal atıkların geri dönüşümü, yapısal atıkların yeniden kullanımı, enerji ve ham madde korunumu anahtar kelimeleri ile (Türkçe ve İngilizce olarak) Google Scholar üzerinden tarama yapılmıştır. Elde edilen bilgiler, hacimce kapladıkları alan ve miktarca büyüklük açısından sıklıkla kullanılan yapı malzemelerinin oluşturduğu atıklar özelinde sınıflandırılmıştır. Bu sınıflama beton, plastik, cam, ahşap, metal, tuğla, alçı malzemeler üzerinden yapılmıştır. Her malzeme özelinde yeniden kullanım ve geri dönüşüm potansiyelleri ortaya konmuştur.

\section{Bulgular}

Araştırmalardan elde edilen veriler göstermektedir ki; dünyadaki enerji ve ham madde kaynakları hızla artan nüfusun gereksinimlerini karşılayabilecek düzeyde değildir. Yapı sektörü etkinliklerinin enerjiyi ve ham madde kaynaklarını tükettiği bilinmektedir. Bu noktada enerji ve ham madde korunumuna yönelik çevreci yaklaşımlar geliştirilmekte, yeşil/sürdürülebilir/çevreci gibi isimlerle anılan yapı üretim süreçleri dikkat çekmektedir. Bu üretim süreçlerinin bağıı olduğu en önemli ölçütlerden birisi enerji ve ham madde korunumudur. Enerjinin ve ham maddelerin korunumu için atıkların geri kazanımı önemlidir. Örneğin beton üretiminde agrega olarak temiz ham madde yerine atık betonların kullanılması hem çevre kirliliğinin azaltılması hem de ham madde korunumu açısından önemlidir. Kimyasallarla boyanmadan kullanılan çelik ürünler geri dönüşüm evresinde daha az işlem gerektireceğinden enerji tüketiminin azalması mümkün olacaktır. Cam, demir ve alüminyum atıkların eritilip geri dönüştürülmesi için gerekli enerji miktarı ile bu ürünlerin ilk elde ediliş enerjileri karşılaştırıldığında geri dönüşüme harcanan enerjinin daha düşük düzeyde olduğu bilinmektedir. Geri dönüşüm işlemi sırasında daha az enerji tüketimi çevre ve ekonomi açısından olumludur. Yapı ürünlerinin yeniden kullanımı ya da geri dönüşümü kadar yapının kısmen ya da bütünüyle yeniden kullanımı da enerji ve ham madde korunumu açısından önemlidir. Bu bağlamda çalışma kapsamında beton, plastik, cam, ahşap, metal, tuğla, alçı atıklar ve bunların yeniden kullanım/geri dönüşüm potansiyelleri enerji ve ham madde tasarrufuna katkıda bulunan eylemler bağlamında ele alınmıştır.

\subsection{Beton Atıkların Değerlendirilme Potansiyelleri}

Beton, dünyada ve Türkiye'de oldukça fazla kullanılan bir yapı malzemesi olmasına rağmen, sebep olduğu atıklarla birçok çevre problemini de beraberinde getirmektedir. Dünya genelinde toplam yapısal atıkların yaklaşık \%40'ını beton atıkları oluşturmaktadır (Oikonomou, 2005). Türkiye'de binaların yaklaşık \%97'sinin betonarme sistem ile üretildiği bilinmektedir (Türkiye İstatistik Kurumu [TüiK], 2020). Bu bağlamda en çok atık oluşturan malzemenin de beton olduğu açıktır. Bu nedenle betonun yeniden kullanılması diğer yapısal atıklara göre, çevresel açıdan daha etkili ve önemli olmaktadır. Bu kadar çok miktarda atığın değerlendirilerek yeniden kullanılması, kirlilikleri ve yeni ham madde gereksinimini azaltacağı için ham madde korunumu/etkinliği açısından önemli çevresel yararlar sağlayacaktır. Betonu oluşturan malzemeler sınırsı kaynak değildir ve doğadaki miktarları gittikçe azalmaktadır. Bu nedenle de beton atıkların değerlendirilmesi kaynak etkinliği sağlamada oldukça etkilidir. Betonda yeniden kullanım; atık durumdaki hazır/prefabrikasyon beton yapı elemanları için mümkün olabilir. 
Beton atıklar amaca göre bazı işlemlerden geçirilerek geri dönüştürülmüş şekilde de kullanılmaktadır. Bu atıklar en çok mekanik işlemlerden geçirilerek (kırılarak) farklı büyüklüklerde agregalar halinde asfalt, yol, nehir seti yapımında; temel inşaatlarında ise dolgu malzemesi olarak kullanılmaktadır. Beton tuğla, kaldırım döşemesi vb. elemanların üretiminde beton atıkları bir bileşen olarak kullanılabilir (Şekil 1). Bu işlemlerle her ne kadar ham madde korunumuna katkı sağlansa da enerji tüketimi konusunda getireceği ek yükten ayrıca söz edilebilir.
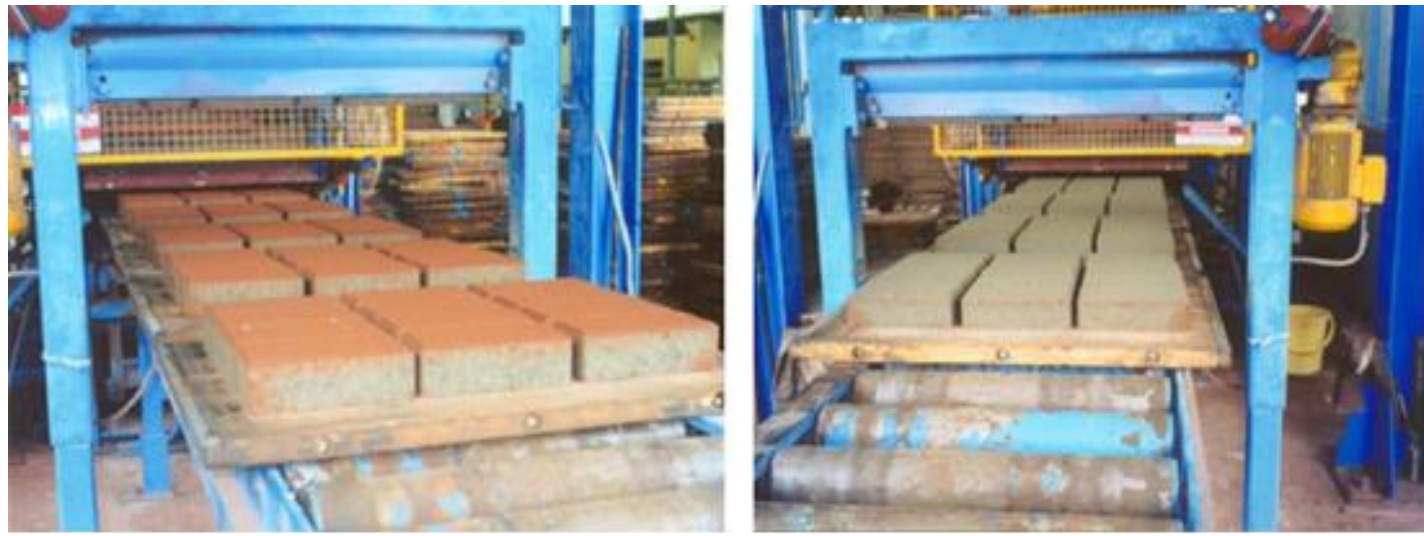

Şekil 1. Geri Dönüştürülmüş Agregadan Kaldırım Bloğu (“Environmentally friendly bricks ve blocks”, 2019)

Türkiye'de, Çevre ve Şehircilik Bakanlığı, Altyapı ve Kentsel Dönüşüm Hizmetleri Genel Müdürlüğünce, TÜBITAK MAM'ın yürütücülüğünde “Inş̧aat ve Yıkıntı Atıklarının Değerlendirilmesi Projesi” kapsamında gerçekleştirilen çalışmalarda beton atığından değişik ikame oranlarında hazır beton, beton boru, bordür, parke taşı, kent mobilyası ve rögar kapağı üretimi gerçekleştirilmiştir (Şekil 2). Yine beton ve karışık atıklardan değişik ikame oranlarında asfalt alt temel, plent miks temel, bitümlü temel ve dolgu tabakası üretilmiştir (Demir, 2020). Betonun önemli bileşenlerinden olan çimento üretiminde de yaklaşık 3600 ton karışık haldeki yapısal atık çimento ham maddesi ile karıştırılarak önce klinker daha sonra da çimento (yeşil çimento) haline getirilmiştir (Çevre ve Şehircilik Bakanlığı [ÇŞB], 2014).

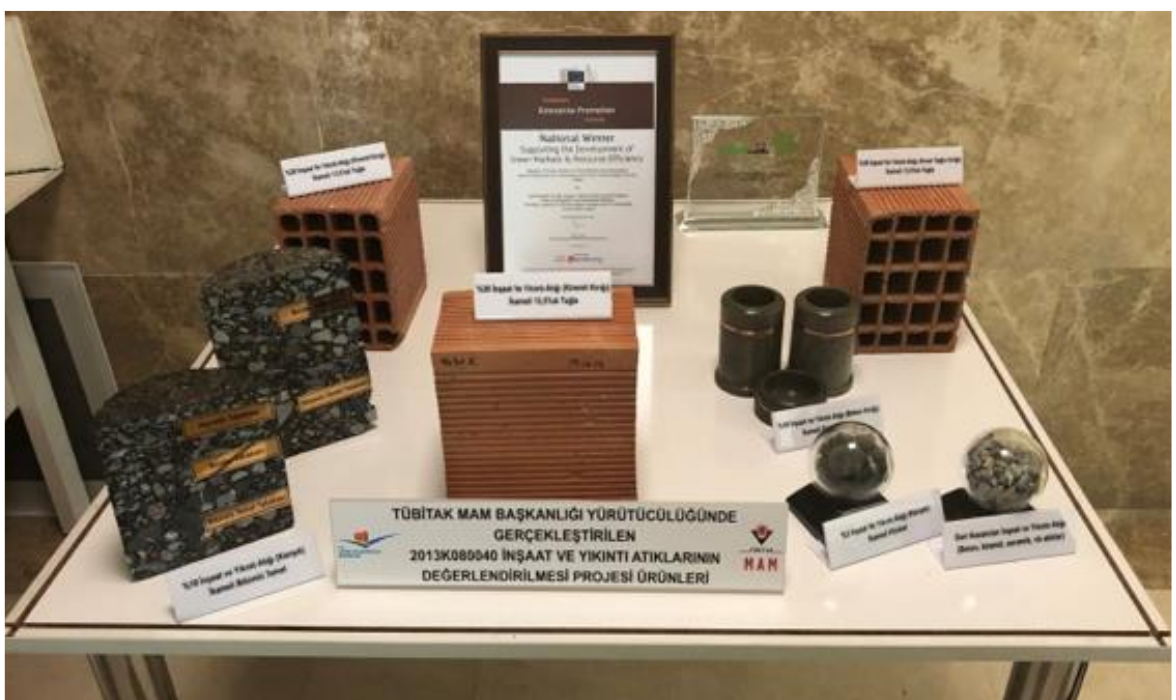

Şekil 2. "Inşaat ve Yıkıntı Atıklarının Değerlendirilmesi Proje” çıktılarından örnekler (Demir, 2020)

\subsection{Plastik Atıkların Değerlendirilme Potansiyelleri}

Günümüzde her alanda kullanımı olan plastiklerin ham maddesinin kolay elde edilmemesi ve üretilirken çok fazla enerji tüketilmesi gibi özellikleri nedeniyle bu atıkların değerlendirilmesi önemlidir. Atık plastikleri yakıp çıkan enerjilerinden faydalanma işleminde, açığa çıkan gazlar insan ve çevre sağlığına zararlı olabileceği için, geri dönüştürülerek çeşitli amaçlarla kullanımı daha çevresel bir yaklaşım olmaktadır. 
Teoride, ham madde ya da işleme kalitesinde olumsuz etki oluşmaksızın PVC (polyvinyl chloride / polivinil klorür) doğramanın geri kazanımı yedi kez tekrar edilebilir. Bu da daha az kaynak kullanımı ve daha düşük bir $\mathrm{CO}_{2}$ emisyon yükü anlamına gelmektedir ("Valuable PVC from plastic windows", 2019).

Plastik yapı ürünlerinin tüketim sonrası potansiyel geri dönüşüm oranları, ürün grubuna bağlı olarak \%5 ile \%70 arasında değişmektedir. Örneğin zemin döşeme ürünlerinin tutkal gibi kirleticilere maruz kalmaları nedeniyle potansiyel geri dönüşüm oranı yaklaşık \%20-30 civarındadır. Pencere doğramalarının ise \%60-70 oranında yüksek kaliteli ürüne dönüştüğü belirtilmektedir (Final Report, 2000).

Yapı sektöründe geniş kullanım alanı bulan plastiklerin diğer yapısal atıklardan ayrılarak, temizlenerek ve düzenlenerek geri dönüşümü yapılabilmektedir. Hollanda'da, geri dönüştürülmüş plastik, yeni plastik üretiminde kullanılırken, yeterli UV dayanıkıı̆ı̆ını sağlamak için $\% 70$ oranında geri dönüştürülmüş malzeme, \%30 oranında sıfır malzeme kullanılmaktadır (Hendriks ve Pietersen, 2000). Mitchell ve diğerleri (2014) tarafından yapılan çalışmada, sınırlı geri dönüşüm potansiyeli barındıran atık kâğıt plastik laminatlar (Paper Plastic Laminates-PPL) ve polipropilen (PP) ekstrüzyon yöntemi ile kompozit granül haline getirilip, enjeksiyon yöntemiyle şekil verilmiştir. Atık PPL-PP kompozitlerde yüksek mekanik özellikler elde edilmiştir. Japonya'da, atık plastikler yüksek ısıda yakıldıktan sonra çok küçük parçacıklar haline getirilip yapay toprak olarak da kullanılmaktadır (Tam ve Tam, 2006). Geri dönüştürülmüş plastik atıklar, sertlikleri ve stabiliteleri nedeniyle agrega ve dolgu maddeleri olarak çimentolu kompozitlere dahil edilebilir, böylece doğadan elde edilen agrega oranı azaltılabilir. Asfaltta agrega olarak atık plastik kullanımının, kaplamanın kayma ve çatlama direncini iyileştirdiği yönünde çalışmalar bulunmaktadır (Awoyera ve Adesina, 2020).

Geri kazanılmış PVC'lerden ayrıca kanalizasyon borusu, çit, geri kazanma konteynırları, yol plakaları, merdiven korkuluğu, marley, kiremit, trafik işaretleri, kar fırtınası deflektörü, piknik masaları ve banklar, pencere, çatı ve zemin kaplaması gibi malzemeler üretilmektedir. Almanya'da yılda $\mathbf{4 5 0 . 0 0 0}$ PVC pencere doğraması geri kazanılmaktadır. Plastik zemin örtü malzemeleri de \%98 oranında tekrar üretimde kullanılabilmektedir (Öztürk, 2005a). Bu sayede enerjinin korunumu yanında atmosfere salınan sera gazı miktarında da azalma sağlanmaktadır.

\subsection{Cam Atıkların Değerlendirilme Potansiyelleri}

Atık haline gelmiş cam malzeme sınırsız olarak yeniden değerlendirilebilmektedir. Binaların yıkım aşamasında kırılmadan çıkartılabilmişse ikinci el ürün olarak yeniden kullanılabilir.

Cam ürünler kalite açısından herhangi bir kayıp olmaksızın \%100 oranında atık camdan üretilebilirler. Kırılmış cam atıkları diğer ham maddeler ile eritilerek geri dönüştürülebilir. Eritme ocağına ilave edilen kullanılmış cam oranı arttıkça ısı oranı azalmaktadır. Bunun nedeni geri kazanılan camın; kum, soda külü ve kireçten daha düşük sıcaklıkta erimesidir. Eritme ocağında tamamı kullanılmış cam ürünler eritildiğinde, enerji tüketiminde $\% 25$ oranında azalma sağlanmaktadır. Ek olarak eski cam kullanımı ile düşük erime noktasında aktif olan soda tüketimi $2 / 3$ 'ten daha fazla oranda azalmaktadır (Savcı ve Dikmen, 2015).

Atık camlar, yeni cam üretiminde olduğu gibi diğer üretimlerde de ham madde kaynağı olarak kullanılabilmektedir. Bir çalışmada atık camların portland kompoze çimento üretiminde kullanımı üzerine araştırma yapılmıştır. Üretilen çimentonun TS EN 197-1'e uygun olduğu ve atık camın çimento üretiminde katkı malzemesi olarak kullanılabileceği ortaya konmuştur (Dayı, Aruntaş, Çavuş ve Şimşek, 2013). Bir diğer çalışmada ise çimentoda $\% 20$ atık cam kullanımının durabilite açısından optimum değerler verdiği saptanmıştır (Khmiri, Samet ve Chaabouni, 2012).

\subsection{Ahşap Atıkların Değerlendirilme Potansiyelleri}

Ahşap, doğadan elde edilen ve tüm dünyada yaygın olarak kullanılan bir yapı malzemesidir. Ham madde kaynağı olan ormanların sürdürülebilirliği için ahşap atıkların değerlendirilmesi önemli bir adımdır. Tüm dünyada, yapısal atıkların içinde bol miktarda ahşap bulunmaktadır. Atık ahşabın yeniden kullanım ve geri dönüşüm sonucu çeşitli kullanım alanları bulunmaktadır. Sağlam ahşap ürünler, temizlenip çivileri çıkarıldıktan ve uygun parçalar haline getirildikten sonra ikinci el ürün olarak 
kullanılabilir. Yeniden kullanım ile doğadan ham madde temini azalacak, beraberinde yeni üretim enerjisi gereksinimi de ortadan kalkacaktır.

Atık küçük ahşap parçalardan özel, hafif bir beton üretilebilir. Kırpık ahşap, eğimli toprak yüzeylere toz halinde serpilen "geofibre" adında bir malzemeye dönüştürülmektedir. Talaş haline getirilmiş atık ahşap, toprak dokusunu güçlendirmek için toprağın üst tabakasıyla karıştırılabilir ve plastikle kaplanarak plastik kereste (laminat parke) yapımında kullanılabilir. Ahşap atık, yalıtım levhası olarak (Tam ve Tam, 2006) ayrıca yakıt ve kömür olarak, güç üretmekte de kullanılabilir. Yakım, ayrıştırma (çürüme, bozulma) veya hidrolizden sonra, atık ahşap veya keresteye gaz haline koyma (gasification) veya ışıl kesim (pyrolysis) işlemleri uygulanarak kimyasal ürün haline getirilebilir (Hendriks ve Pietersen, 2000).

\subsection{Demir İçeren Metal Atıkların Değerlendirilme Potansiyelleri}

Yapı alanında en yaygın kullanılan metallerden biri olan çelik, metalik demirin karbon, manganez, silisyum, fosfor, kükürt ve diğer birçok elementle alaşım, bileşim ve karışımıyla oluşan bir malzemedir. İçeriğindeki demirin allotropik (kristal yapısının sıcaklığa bağlı olarak değişen) özellik göstermesi, ısıl işlem ve alaşımlama ile farklı özellikler kazanabilmesi sayesinde geri dönüşüm özelliği en yüksek endüstriyel malzemedir (Kayır, 2001).

Demir-çelik sektöründe ana girdiler demir cevheri, hurda ve enerjidir (Yıldız, 2013). Üretilen her $100 \mathrm{~kg}$ çeliğin 40 kg'ı geri dönüşümden sağlanmaktadır (Kayır, 2001). Sektörde, elektrik ark ocaklı kuruluşlarda ham madde olarak kullanılan hurdanın yaklaşık \%70'i ise ithal edilmektedir (Yıldız, 2013). Çeliğin üretim aşamasında kullanılan metallerin doğadan çıkarılması oldukça zor ve çevresel zararları olan bir süreçtir. Yeni üretimlerde ham madde olarak, kullanılmış yani hurda haline gelmiş çeliğin kullanıldığı da dikkate alınırsa geri dönüştürülerek değerlendirme ham madde korunumu açısından oldukça önemlidir

Kullanılmış çelik yeniden kullanıldığında ve geri dönüştürüldüğünde;

- \%74 oranında enerji ve \%90 oranında ham madde korunduğu,

- \%40 oranında su tüketiminin azaltıldığı,

- \%76 oranında atık su kirlenmesinde, \%86 oranında hava kirlenmesinde ve \%97 oranında maden atıklarında azalma olduğu belirtilmektedir (Öztürk, 2004).

1000 kg kullanılmış çelik geri kazanılıp tekrar çelik üretiminde kullanıldığında; 1050 kg demir cevheri, $454 \mathrm{~kg}$ kok kömürü ve $55 \mathrm{~kg}$ kireç taşı daha az kullanılır (Öztürk, 2004). Tüm dünyada, demir içeren metallerin geri dönüşümü için çok gelişmiş bir pazar mevcuttur. Çelik ürünlerin çeşitli kimyasallarla boyanmaksızın kullanılması durumunda geri dönüşüm sürecinde daha az işlem gerekecek böylece enerji tüketimi de azalacaktır.

\subsection{Demir İçermeyen Metal Atıkların Değerlendirilme Potansiyelleri}

Yapısal atıkların içinde olabilecek başlıca demir içermeyen metaller alüminyum, bakır, kurşun ve çinkodur. Bunlardan en çok kullanılan alüminyum, yeryüzünde oksijen ve silisten sonra en fazla miktarda bulunan (\%8) bulunan metallerdendir (Öztürk, 2005b). İnşaat sektörü yılda; Avrupa'da 1,2 milyon ton, ABD'de 1,05 milyon ton, Japonya'da 915.000 ton alüminyum kullanmaktadır. Türkiye'de alüminyum kullanımı yılda yaklaşık üç kg/kişi olup, bu miktar gelişmiş ülkelerin ortalamasına göre beşaltı kat daha düşüktür. Alüminyum kullanımının sağladığı yararlar dikkate alındığında, Türkiye'de alüminyum kullanımı için büyük bir potansiyel olduğu görülmektedir. Türkiye'de, alüminyum ekstrüzyon, yassı-ürünler, döküm ürünleri ve iletkenlerin geniş çapta üretimi, özel sektör tarafından gerçekleştirilmektedir. Yıllık üretim kapasitesi, yaklaşık olarak; ekstrüzyon ürünlerinde 400.000 450.000 ton, yassı ürünlerde 150.000 ton, döküm ürünlerinde 180.000 ton, iletkenlerde ise 60.000 tondur (Günay, 2006). Alüminyum, inşaat sektöründe binaların çatı ve cephe kaplamalarında, kapı ve pencerelerinde, merdivenlerde, çatı iskeletinde, inşaat iskelelerinde ve dekoratif levha olarak kullanılmaktadır.

Alüminyum üretiminde boksit gibi doğal kaynakları kullanmak yoğun enerji tüketen ve pahalı bir sistemdir. Kullanılmış alüminyumun geri dönüştürülerek yeniden kullanımı ile daha az enerji ve ham 
madde tüketimi sağlamak mümkündür. Kullanılmış alüminyumun tekrar yeni alüminyum üretiminde kullanımı ile sera gazı emisyonu \%95 ve su kirlenmesi \%97 oranında azaltılabilir (Çevre ve Şehircilik Bakanlığı [ÇŞB], 2019). Bir ton kullanılmış alüminyum tekrar alüminyum üretiminde kullanıldığında; $1300 \mathrm{~kg}$ boksit, 15000 litre soğutma suyu, 860 litre süreç suyu daha az kullanılır, $11 \mathrm{~kg} \mathrm{SO}$ ve $2000 \mathrm{~kg}$ $\mathrm{CO}_{2}$ emisyonu daha az oluşur (Alan, 2008).

Alüminyum malzemelerin \%100 geri kazanılabilir olması boksit madeni kaynağının ve enerjinin korunmasına katkı sağlar. Bir kg alüminyum geri kazanıldığında; sekiz kg boksit madeni, dört kg kimyasal madde korunmuş ve $14 \mathrm{kWh}$ elektrik enerjisi tüketilmemiş olur. Kullanılmış alüminyum geri kazanılıp yeni alüminyum üretiminde kullanıldığında; baca gazı kirletici emisyonu \%99, atık su kirlenmesi \%97 ve sera gazı emisyonu \%95 oranında azaltılabilir (Öztürk, 2005b). Alüminyumu eritip geri dönüştürmek için ilk üretim enerjisinin \%10-\%20'si kadar enerji yeterlidir (Sev, 2009). Bu bağlamda kullanılmış alüminyumun geri kazanımı daha az enerji ve ham madde tüketimi açısından önemlidir.

\subsection{Tuğla Atıkların Değerlendirilme Potansiyelleri}

Tuğla, ham madde eldesi oldukça kolay ve diğer malzemelere oranla ucuz bir malzemedir. Bununla birlikte çalışmalar göstermiştir ki yeni üretilen bir ton tuğla $258 \mathrm{~kg} \mathrm{CO}$ emisyonu açığa çıkarırken, bir ton geri dönüştürülmüş tuğla $2,7 \mathrm{~kg} \mathrm{CO}$ emisyonu yaymaktadır. Bu veriler yeni tuğlaların üretiminde geri dönüştürülmüş tuğlalara göre 95 kat daha fazla $\mathrm{CO} 2$ yaydığını göstermektedir ki çevresel açıdan büyük bir yük demektir ("Recycled bricks", 2021). Bu nedenle ham madde ve çevre korunumu ile enerji tüketiminin azaltılması için geri dönüşümüne önem verilmesi gerekmektedir.

Tuğla malzemelerin geri dönüşümü söz konusu olduğunda, beton malzemeye uygulandığı gibi daha çok mekanik yollarla parçalama işlemleri yapılmaktadır. Tuğlalar, yıkım atıklarından harç ile kirletilmiş, alçı ile sıvanmış, beton ve ahşap gibi farklı malzemeler ile karıştııımış olarak çıkabilir. Kullanılabilir tuğlanın ayrılması genelde çok zahmetlidir ve elle sınıflandırmayı gerektirir. Tuğlaların yapıdan kirli olarak çıkarılıp temizlenerek kullanımları, onları ekonomik olarak sıfır tuğladan çok daha pahalı hale getirmektedir. Bu sorunu çözmek amacıyla Avrupa Birliği tarafından finanse edilen REBRICK projesi ile yeniden kullanım için sağlam tuğlaları ayıran ve temizleyen yeni bir sistem geliştirilmiştir. REBRICK projesinin tamamlanmasından sonraki ikinci yılda 24.000 tona varan yıllık atık azalması sağlayabileceği öngörülmüştür. Yeniden kullanılan her tuğlanın, yeni tuğlalarla yapılan binalara kıyasla 0,5 kilo $\mathrm{CO}_{2}$ emisyonu tasarrufu sağladığı belirtilmiştir (CORDIS, 2013).

Kyoto'da 2004'te yapılan saha çalışmasında, parçalanmış tuğlalar yakılarak ince uçucu küllere çevrilmiştir. Son yıllarda, Hong Kong'da tuğlalar genelde dolgu malzemelerinin içine katılmaktadır. Parçalanmış tuğlalar yaygın olarak yol kenarlarında dolgu malzemesi ve peyzajda süs olarak kullanılmaktadır (Tam ve Tam, 2006) (Şekil 3). Son yıllarda Türkiye'de yapılan çalışmalarda sıvalı tuğla atığı ve kiremit atığından değişik ikame oranlarında 13,5'luk düşey delikli "yeşil tuğla" üretimi gerçekleştirilmiştir (Demir, 2020). Üretilen her tuğla, karakteristiklerini ve performans şartlarını düzenleyen TS EN 771-1 standardı kapsamında deneylere tabi tutulmuş, alınan ilk sonuçların oldukça memnuniyet verici olduğu görülmüştür (ÇŞB, 2014) (Şekil 2). 


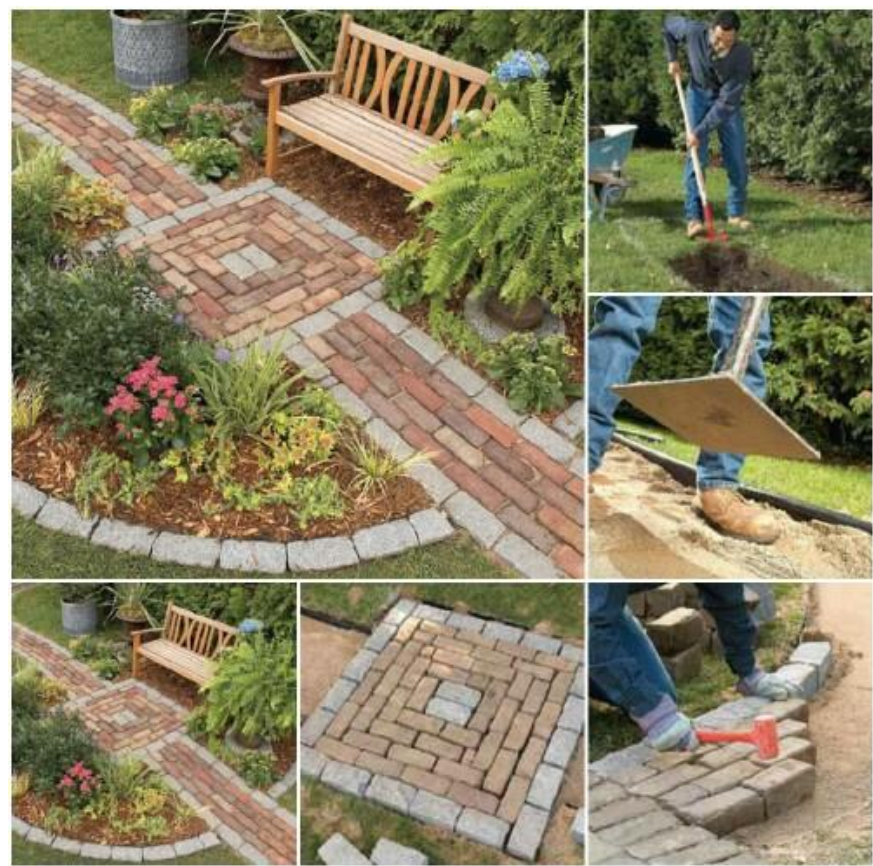

Şekil 3. Tuğlanın peyzajda yeniden kullanımı (Build a brick path, 2020)

\subsection{Alçı Atıkların Değerlendirilme Potansiyelleri}

Amerika ve Avrupa başta olmak üzere dünyada kullanılan başlıca duvar malzemesi olan alçı/alçı levha ürünlerinin üretimi her yıl toplam 80 milyon ton civarındadır. Avrupa, Amerika ve Asya bu üretimin $\% 85$ 'ini oluşturmaktadır. Bununla birlikte her yıl yaklaşık 15 milyon ton, günlük olarak 40.000 tondan fazla atık alçı depolama alanlarına gönderilmektedir (Ahmed, Ugai ve Kamei, 2011). Avrupa ve Amerika'da atık alçı levhaların uygun toplama yöntemleri ile geri dönüşümünü yapan çeşitli firmalar bulunmaktadır. Alçı levha üreticileri, ürünlerine Çevresel Ürün Beyanı (Environmental Product Declaration-EPD) almak ve LEED, BREEAM gibi yapı sertifika sistemlerine uygun alçı levha malzemeler üretebilmek amacıyla yeni ürün üretimlerinde geri dönüştürülmüş ürün kullanmaktadır (Lund-Nielsen, 2007).

Pinheiro ve Camarini'nin (2015) çalışması, alçı levhaların ve alçı taşının kalsinasyon ile alçıya; alçının ise hidratasyon ile yeniden alçı taşına dönüşebildiğini, bu reaksiyonların tersine çevrilebilirliğini göstermektedir. Alçı ürünler "kapalı-döngü" (closed-loop) geri dönüşümün mümkün olduğu, diğer bir deyişle tekrardan aynı ürünün üretiminde kendi atığının ham madde olarak kullanılabildiği az sayıdaki yapı malzemeleri arasında sayılabilir. Bu bağlamda atık alçı levhaların yeniden kullanım ya da yeni levhaların üretimi için ham madde kaynağı olma potansiyelini değerlendirmek önemlidir (Thormark, 2001). Atık alçı levhalar teoride yeniden kullanım potansiyeli barındırsa da gerek hijyen gerekse organik atıklarla bir arada depolanma koşulları nedeniyle insan sağlığına zararlı gazların oluşumuna sebep olabilmektedir.

Alçı ürünler ham madde eldesinden başlayarak üretim, kullanım ve yaşam sonu süreçleri boyunca değerlendirildiğinde; standart alçı levhanın her bir $\mathrm{m}^{2}$ si için karbon ayak izi 1,8 $\mathrm{kg} \mathrm{CO}_{2}$ eşdeğeri iken, bir kg el ile uygulanan yapı alçısı için bu değer 0,16 kg CO${ }_{2}^{\prime}$ dir ("Büyük üretimin küçük ayak izi", 2021). Inşaat sektöründeki diğer yapı malzemeleri ile kıyaslandığında, alçı ve alçı levha ürünlerin düşük karbon ayak izine sahip olduğu açıktır. Ham maddesinin doğada bol bulunması, düşük pişirme sıcaklığına sahip olması ve kolay öğütülmesine bağlı olarak üretim sırasında enerji maliyeti düşük bir malzemedir. Bu bağlamda enerji korunumu ve kaynakların etkin kullanımı açısından büyük avantajlara sahip olduğu söylenebilir (Sev ve Görgülü, 2012).

Atık alçı, priz süresinin ayarlanması amacıyla çimento üretiminde kullanılmaktadır. Chandara, Azizli, Ahmad ve Sakai (2009), çalışmalarında portland çimentosunda doğal alçı yerine atık alçının kullanılabileceğini ve alternatif bir ham madde oluşturarak doğal alçı kaynaklarının korunabileceğini belirtmektedir. 


\section{Sonuç ve Öneriler}

Bu çalışma kapsamında hacimce kapladıkları alan ve miktarca büyüklük açısından sıklıkla kullanılan yapı malzemelerinin oluşturduğu atık türlerinden beton, plastik, cam, ahşap, metal, tuğla ve alçı atıkların yeniden kullanımı ve geri dönüşümü yapılarak enerji ve ham madde korunumu sağlanacağı varsayımıyla bir irdeleme yapılmıştır. Belirtilen atık türleri için yeniden kullanım ve geri dönüşüm potansiyelleri belirtilmiştir (Çizelge 1). Yeniden kullanım ile bir ürünün yararlı ömrünü uzatarak yeni bir üretim yapılmasının önüne geçilmekte, böylece yeni üretim için gereken enerji ve doğadan elde edilen ham madde kaynağı neredeyse sıfır düzeyine indirilmektedir. Geri dönüşüm yoluyla da doğadan alınan birincil ham madde düzeyi düşürülmektedir. Geri dönüşümde yeni bir üretim süreci olacağından enerji kullanımı söz konusu olsa da çalışma kapsamında görüldüğü üzere geri dönüştürülmüş ürünlerin ham madde olarak kullanıldığı üretimlerde enerjinin de daha düşük düzeylerde kullanımı mümkündür. Çalışma kapsamında incelenen yapısal atıkların hepsinde geri dönüşüm potansiyeli bulunsa da süreçlerin ve üretilen ürünlerin verimlilik düzeyleri farklılık gösterebilecektir. Örneğin herhangi bir kimyasal işlem uygulanmayan (koruyucu boya vb.) çeliğin geri dönüşümü kimyasal işlem uygulanana göre daha kolay ve verimlidir. Benzer şekilde, incelenen atıkların yeniden kullanımı ve geri dönüşümü ile ham madde ve enerji korunumu açısından yarar sağlanmakla birlikte verimlilik düzeyleri farklılık gösterebilir.

Çizelge 1. Yapısal atıkların değerlendirilme ve yararlılık potansiyelleri

\begin{tabular}{lcccc}
\hline \multirow{2}{*}{ Yapısal Atık Türü } & \multicolumn{2}{c}{ Değerlendirilme Potansiyeli } & \multicolumn{2}{c}{ Yararlılık Potansiyeli } \\
\cline { 2 - 5 } & Yeniden Kullanım & Geri Dönüşüm & $\begin{array}{c}\text { Ham Madde } \\
\text { Korunumu }\end{array}$ & Enerji Korunumu \\
\hline Beton & $\checkmark$ & $\checkmark$ & $\checkmark$ & - \\
\hline Plastik & $\checkmark$ & $\checkmark$ & $\checkmark$ & $\checkmark$ \\
\hline Cam & $\checkmark$ & $\checkmark$ & $\checkmark$ & $\checkmark$ \\
\hline Ahşap & $\checkmark$ & $\checkmark$ & $\checkmark$ & $\checkmark$ \\
\hline Demir İçeren Metal & $\checkmark$ & $\checkmark$ & $\checkmark$ & $\checkmark$ \\
\hline Demir İçermeyen Metal & $\checkmark$ & $\checkmark$ & $\checkmark$ & $\checkmark$ \\
\hline Tuğla & $\checkmark$ & $\checkmark$ & $\checkmark$ & $\checkmark$ \\
\hline Alçı & - & $\checkmark$ & $\checkmark$ & $\checkmark$ \\
\hline
\end{tabular}

Yapı ürünleri için yeniden kullanım ve geri dönüşüm potansiyellerinin bilinerek yapısal atıkların yönetilmesi, olabildiğince ikinci el ürün kullanımının desteklenmesi, bu anlamda ikinci el ürün pazarlarının artması, yapı sektöründeki bütün katılımcıların (tasarımcı, yüklenici, kullanıcı vb.) bu bilinç düzeyine ulaşması için gerekli çalışmaların yapılması ve süreklilik göstermesi önemlidir. Bu şekilde enerji kullanımının azalacağı, ham madde kaynaklarının korunacağı, böylece çevresel ve ekonomik yararlar sağlanacağı düşünülmektedir.

Yapı sektörü uygulamalarına yönelik olarak yapılacak çalışmalar doğal çevrenin ve canlı sağlığının korunması ile ülke ekonomisinin güçlenmesi açısından önem taşımaktadır. Özellikle yapıların yaşam süreçlerinde (yapım, kullanım, söküm/yıkım) ve yapı ürünlerinin yaşam süreçlerinde (ham madde edinimi, ürünün üretimi, satışı, taşınması, yapıya uygulanması, kullanımı, geri dönüşümü, yok edilmesi) oluşan yapısal atıkların çevre, canlı sağlığı ve ülke ekonomisi üzerindeki olumsuz etkileri dikkate alındığında bu alanda yapılan/yapılacak çalışmaların önemi açıktır. Dünya geneline bakıldığında enerji kullanımının yarısının yapılarla ilişkili faaliyetlerde tüketildiği söylenebilir. Bu nedenle çevre sorunlarını gidermek, ülke ekonomisine katkı sağlamak amacıyla, enerji kullanımını ve ham madde tüketimini azaltmak için yapısal atık yönetimi ile ilgili konuların yapı endüstrisinin bir parçası olması gerektiği düşünülmektedir.

\section{Teşekkür ve Bilgi Notu}

Bu çalışma Erciyes Üniversitesi Bilimsel Araştırma Projeleri Koordinasyon Birimi tarafından desteklenmiştir (Proje No: FBA-2016-6627). 4-5 Mayıs 2018 tarihlerinde gerçekleştirilen III. Uluslararası Mühendislik Mimarlık ve Tasarım Kongresi'nde sözel bildiri olarak sunulmuştur. Makalede, ulusal ve uluslararası araştırma ve yayın etiğine uyulmuştur. Çalışmada etik kurul izni gerekmemiştir. 


\section{Yazar Katkısı ve Çıkar Çatışması Beyan Bilgisi}

Makalede tüm yazarlar aynı oranda katkıda bulunmuştur. Herhangi bir çıkar çatışması bulunmamaktadır.

\section{Kaynaklar}

Ahmed, A., Ugai, K. ve Kamei, T. (2011). Investigation of recycled gypsum in conjunction with waste plastic trays for ground Improvement. Construction and Building Materials, 25(1), 208-217.

Ajayi, S. O., Oyedele, L. O., Bilal, M., Akinade, O. O., Alaka, H. A. ve Owolabii, H. A. (2017). Critical management practices influencing on-site waste minimization in construction projects. Waste Management, 59, 330-339.

Alan, S. (2008). Alüminyum Raporu. Orta Anadolu Ihracatçı Birlikleri Genel Sekreterliği Raporu.

Awoyera, P. O. ve Adesina, A. (2020). Plastic wastes to construction products: Status, limitations and future perspective. Case Studies in Construction Materials, 12(2020). https://doi.org/10.1016/j.cscm.2020.e00330.

Building Research Establishment Environmental Assessment Method. (2016). International New Construction, Technical Manual. Erişim Adresi (02.04.2019): https://www.breeam.com/BREEAMInt2016SchemeDocument/\#resources/output/10_pdf/a4_ pdf/nc_pdf_printing/sd233_nc_int_2016_print.pdf

Build a brick path._(2020, 24 Mart). Erişim adresi: https://www.enviromate.co.uk/blog/twentyincredibly-creative-ways-reuse-old-bricks

Büyük üretimin küçük ayak izi. (2021, 24 Nisan). Erişim adresi: http://www.dalsan.com.tr/tr/Sayfa/Index/40

Cengiz, A. E., Karadağ, A. A. ve Alpay, C. O. (2014). Çevre dostu binalar: Yeşil binalar. Uluslararası Hakemli Tasarım ve Mimarlık Dergisi, 1(1), 24-33.

Chandara, C., Azizli, K. A. M., Ahmad, Z. A. ve Sakai, E. (2009). Use of waste gypsum to replace natural gypsum as set retarders in portland cement. Waste Management, 29(5), 1675-1679.

CORDIS. (2013). New Old Bricks for the Construction Industry. Erişim Adresi (22.04.2021): https://cordis.europa.eu/article/id/36066-new-old-bricks-for-the-construction-industry

Çevre ve Şehircilik Bakanlığı. (2014). İnşaat ve Yıkıntı Atıklarından illk Endüstriyel Uygulama Tamamlanarak "Yeşil Tuğla" ve "Yeşil Çimento" Üretildi. Erişim Adresi (14.04.2021): https://altyapi.csb.gov.tr/insaat-ve-yikinti-atiklarindan-ilk-endustriyel-uygulamatamamlanarak-yesil-tugla-ve-yesil-cimento-uretildi---haber-13871

Çevre ve Şehircilik Bakanlığı. (2019). Atıkların Geri Kazanımı. Erişim Adresi (14.04.2021): https://webdosya.csb.gov.tr/db/destek/icerikler/08_at-klar-n_ger-_kazan-m-_brosur20191128080715.pdf

Dayı, M., Aruntaş, H. Y., Çavuş, M. ve Şimşek, O. (2013). Zeolit, uçucu kül ve atık cam malzemelerin portland kompoze çimento üretiminde kullanılabilirliğinin araştırılması. Journal of the Faculty of Engineering and Architecture of Gazi University, 28(3), 491-499.

Demir, B. (2020). Belediyelerde inşaat yıkıntı atığı yönetiminin geleceğine yön verecek iki temel enstrüman: Seçici yıkım ve geri kazanım. iller ve Belediyeler Dergisi, Mayıs-Haziran 2020, 54-58.

Environmentally friendly bricks ve blocks from recycled aggregates. (2019, 4 Nisan). Erişim adresi: http://www.zn903.com/cecspoon/gd.pdf

Final Report. (2000). Mechanical Recycling of PVC Waste. Study for DG XI of the European Commission, Basel/Milan/Lyngby.

Günay, D. (2006). Alüminyum Sektörü Hakkında Bir Değerlendirme. Türkiye Kalkınma Bankası A.Ş., Ekonomik ve Sosyal Araştırmalar Müdürlüğü, Ankara. 
Hendriks, C. F. ve Pietersen, H. S. (Ed.) (2000). Sustainable Raw Materials: Construction and Demolition Waste. RILEM Publication, 201p, Cachan Cedex, Fransa.

Huang, W. L, Lin, D. H, Chang, N. B. ve Lin, K. S. (2002). Recycling of construction and demolition waste via a mechanical sorting process. Resources, Conservation and Recycling, 37, 23-37.

Kayır, Y. Z. (2001). 1. Demir-Çelik Sempozyumu ve Sergisi açılış konuşması. Erişim Adresi (02.04.2021): http://www.metalurji.org.tr/dergi/dergi127/der127_9.pdf

Khmiri, A., Samet, B. ve Chaabouni, M. (2012). A cross mixture design to optimise the formulation of a ground waste glass blended cement. Cement and Concrete Composites, 28(1), 680-686.

LEED. (2019). V4 for Building Design and Construction. Erişim Adresi (02.04.2019): https://www.usgbc.org/resources/leed-v4-building-design-and-construction-current-version

Li, H., Chen, Z. ve Wong, C. T. (2003). Barcode technology for an incentive reward program to reduce construction wastes. Computer-Aided Civil and Infrastructure Engineering, 18(4), 313-324.

Lund-Nielsen, H. (2007). Experience in gypsum recycling on three continents. Global Gypsum Magazine, May 2007, 26-33.

Mitchell, J., Vandeperre, L., Dvorak, R., Kosior, E., Tarverdi, K. ve Cheeseman, C. (2014). Recycling disposable cups into paper plastic composites. Waste Management, 34, 2113-2119.

Oikonomou, N. D. (2005). Recycled concrete aggregates. Cement and Concrete Composites, 27(2), 315318.

Öztürk, M. (2004). Kullanılmış çeliğin geri kazanılması. Erişim Adresi (21.01.2019): http://www.bilgin.net/COBcelik.htm

Öztürk, M. (2005a). Daha iyi bir gelecek için plastiklerin geri kazanımı. Erişim Adresi (21.01.2019): https://docplayer.biz.tr/903808-Cevre-ve-orman-bakanligi.html

Öztürk, M. (2005b). Kullanılmış alüminyum malzemeleri geri kazanılması. Erişim Adresi (21.01.2019): https://www.cevremuhendisleri.net/konu/kullanilmis-aluminyum-malzemelerin-gerikazanilmasi.2145/

Pinheiro S. M. M. ve Camarini, G. (2015). Characteristics of gypsum recycling in different cycles. International Journal of Engineering and Technology, 7, 215-218.

Recycled bricks reduces $\mathrm{CO}_{2}$ emissions enormously. (2021, 24 Nisan). Erişim adresi: https://henninglarsen.com/en/news/archive/2017/09/28-recycled-bricks-reduces-co2emissions-by-1-millionplus-kg/

Savcı, S. ve Dikmen, Ç. B. (2015). İnşaat Sektöründe Geri Dönüşüm Kaynağı Olarak Cam Malzemelerin Yeniden Kullanımı. 2nd International Sustainable Buildings Symposium, 28-30 Mayıs, Ankara, s. 694-697.

Sev, A. (2009). Sürdürülebilir Mimarlık. Yapı-Endüstri Merkezi Yayınları, 223p, İstanbul.

Sev, A. ve Görgülü, C. (2012). Malzemede yeşil algı ve beton örneği. Mimarlıkta Malzeme, 7(21), 40-48.

Tam, V. W. Y. ve Tam, C. M. (2006). A review on the viable technology for construction waste recycling. Resources Conservation and Recycling, 47(3), 209-221.

Thormark, C. (2001). Conservation of energy and natural resources by recycling building waste. Resources Conservation and Recycling, 33(2), 113-130.

Türkiye İstatistik Kurumu. (2020). Yapı Kullanma İzin Belgesine Göre Kullanma Amacı ve Taşıyıcı Sistem. Erişim Adresi (20.04.2021): https://data.tuik.gov.tr/Bulten/Index?p=Yapi-Izin-IstatistikleriOcak-Eylul,-2020-33782

Valuable PVC from plastic windows. (2019, 25 Nisan). Erişim adresi: https://www.recyclingmagazine.com/2017/03/20/valuable-pvc-plastic-windows/ 
Journal of Architectural Sciences and Applications, 2021, 6 (2), 526-537.

Yıldız, K. (2013). Demir-çelik metalürjisi. Erişim Adresi (26.01.2021): http://content.Ims.sabis.sakarya.edu.tr/Uploads/48956/41772/demircelik_dersnotu.pdf 